\title{
Life-threatening event during skin-to-skin contact in the delivery room
}

\author{
Brett Schrewe, ${ }^{1}$ Annie Janvier, ${ }^{2}$ Keith Barrington ${ }^{2}$ \\ ${ }^{1}$ Department of Pediatrics, Montreal Children's Hospital, Montreal, Quebec, Canada \\ ${ }^{2}$ Department of Neonatology, Sainte Justine University Hospital, University of Montreal, Montreal, Quebec, Canada \\ Correspondence to Keith Barrington, keith.barrington@umontreal.ca
}

\section{Summary}

After an uncomplicated term delivery, a newborn infant experienced a life-threatening even a few minutes after being born. Few such events have been described before, they may be due to suffocation; minor changes in surveillance can probably prevent these potentially devastating events.

\section{BACKGROUND}

A few previous cases of life-threatening events occurring after uncomplicated deliveries at term have been reported, but none from North America. Increased awareness may help preventing further such occurrences.

\section{CASE PRESENTATION}

A previously healthy 20 -year-old primigravid woman, at 39 weeks and 5 days gestation presented to our tertiary care hospital in active labour of 4-h duration. Her pregnancy had been uncomplicated with an unremarkable 19-week ultrasound and negative serologies. She was HIV and hepatitis B negative, and rubella immune. Her group B Streptococcus cultures (done at 37 weeks) were positive. She presented to the hospital with the cervix dilated to $9 \mathrm{~cm}$ and completely effaced with regular contractions. She delivered rapidly and only received antimicrobial prophylaxis of $2-h$ duration before delivery. She had spontaneous rupture of membranes within $1 \mathrm{~h}$ of birth with thin meconium present. The fetal tracing was normal throughout. One loose nuchal loop of umbilical cord was noted. She delivered a vigorous male infant of $3.1 \mathrm{~kg}$ and with Apgars of 9 and 9 at 1 and 5 min. The cord pH was: 7.32 and $\mathrm{PCO}_{2}$ was 35 with a base excess of -1.2 . The baby was handed to his mother and placed prone, on the mother's chest, for skin-to-skin contact.

The obstetrician subsequently delivered the placenta and started repairing the episiotomy.

Ten minutes later, while the obstetrician was performing this task, the nurse came to weigh the baby and noticed him to be pale, non-reactive, apnoeic, with no detectable heart rate and immediately called the neonatology team while performing the initial resuscitation steps. Two minutes later, the neonatal team arrived and found a blotchy nonreactive baby with no heart rate. In total, 2 min of chest compressions were required before a heart rate was detected, which then remained above 100 . Ten minutes of positive pressure ventilation were given; after $2 \mathrm{~min}$, the baby began making gasping efforts. At 10 min of age, the team was able to discontinue positive pressure ventilation and the infant was transferred to the neonatal intensive care unit, requiring continuous positive airways pressure for $1 \mathrm{~h}$. His initial blood gas, 30 min after the event, was pH 7.23, $\mathrm{PCO}_{2} 38$, serum bicarbonate of 15.5 and a base excess of -10.6 .

\section{INVESTIGATIONS}

A full investigation for possible sepsis was performed, including blood, urine and cerebrospinal fluid (CSF) cultures and CSF PCR for herpes and enterovirus. All results were negative and antibiotics were discontinued after $48 \mathrm{~h}$.

\section{TREATMENT}

Supplemental oxygen was necessary for the first $12 \mathrm{~h}$ of life, but he had a normal chest $x$-ray and from day 2 of life, saturated above $97 \%$ in room air. He demonstrated signs consistent with a Sarnat stage I asphyxia: he was tremulous, irritable and jittery. He did not have any metabolic abnormalities. He initially had some difficulty bottle-feeding and required parenteral nutritional support for a total of 3 days.

\section{OUTCOME AND FOLLOW-UP}

Initial ECG (12 h after event) showed signs consistent with mild right-ventricular hypertrophy, which resolved by the third day of life when the ECG was normal. Infectious and metabolic investigations were non-contributory; ampicillin and gentamicin were discontinued after $48 \mathrm{~h}$. He was discharged home on the fifth day of life following 2 days of phototherapy for mild indirect hyperbilirubinemia and had no further complications. Six months after the event, the baby is doing well with his growth and development.

\section{DISCUSSION}

An apnoeic episode requiring resuscitation and intensive care support in a term baby who appears otherwise healthy at birth during a period of early skin-to-skin care by the mother has previously been reported. We reviewed the French and English literature by searching PubMed in November 2008 using the search terms 'sudden death AND newborn', we also used the 'related articles' link from the 
first relevant article found and eventually discovered seven articles reporting sudden unexpected serious adverse events during the first $12 \mathrm{~h}$ of life.

Hays et al reports, in a letter to the editor, 11 cases of term infants with uneventful pregnancies and deliveries who all had respiratory arrest within the first $2 \mathrm{~h}$ of life requiring extensive resuscitation efforts. ${ }^{1}$ All had been placed in prone position on their mother's chest or abdomen; nine of them had negative cultures, and seven had been born to primigravid mothers. Espagne et al reports the case of a term infant born to a primigravida mother with an otherwise uncomplicated prenatal and perinatal course, found in cardiorespiratory arrest against her chest who subsequently died a week later despite extensive reanimation efforts. ${ }^{2}$ Gatti et al report six term infants born to primiparous mothers and placed prone against their mother's chest. ${ }^{3}$ All were found in cardiorespiratory arrest within the first $2 \mathrm{~h}$ of life; five of six subsequently died. Rodriguez-Alarcon et al reported 29 cases between 1975 and 1991, 21 of whom ultimately died, where the cardiorespiratory arrest occurred after being placed prone on their mother's chest. ${ }^{4}$ Their results indicated that these incidents were more likely in the early morning and on weekends. Dageville et al reported that over a year encompassing 62968 live births of term infants with previously uncomplicated course, two experienced apparently life-threatening events, both of whom were born to primiparous mothers, placed skin-to-skin and subsequently left without monitoring. In 11 cases reported by Branger et $a l^{6}$ the position of the infant was known in eight, and in five of these cases, the infant was in skin-toskin contact against the mother's chest. Seven of the 11 died. Finally, Toker-Maimon et al reported the cases of two term infants with otherwise uneventful courses placed on their mothers for unobserved breastfeeding that needed resuscitation, extensive support and both of whom who ended up severely neurologically impaired. ${ }^{7}$

A total of 59 cases have therefore been reported, of whom only three were not in skin-to-skin contact with the mother at the time of the event. We cannot calculate the relative risk of being in skin-to-skin contact compared to being in a crib, as we do not know, in the various countries represented, the likely duration of time during the first few hours of life that an infant spends in skin-to-skin contact compared to being in a crib or other position. Nevertheless, the overwhelming frequency of these episodes occurring in skin-to-skin contact suggests that it is a risk factor, even if almost all episodes of skin-to-skin contact are uneventful.

All of the previous case reports and series were from Europe or Israel. We were unable to find a similar description of cases in North America. In the series of in-hospital life-threatening events reported by Burchfield and Rawlings ${ }^{8}$ from Florida, the youngest infant was $15 \mathrm{~h}$ old.

Although immediate skin-to-skin contact after birth has apparent benefits for the mother and is generally safe, our case and these reports suggest a rare association with unexpected acute life-threatening deterioration. The benefits of increased success of breastfeeding and enhanced motherinfant interaction should not be sacrificed because of these rare events. Rather, we feel that during this critical period of adaptation of the infant, a responsible person should be assigned to non-invasively observe the infant for signs of distress or depression.
The mechanisms of such events may include suffocation, in which case an association with maternal obesity or large breasts might be expected, but has not been reported. Many of the infants reported have been found prone, which suggest a common mechanism with later sudden infant death syndrome; re-breathing of expired air and progressive asphyxia may thus be implicated in both. As having the baby prone on the chest is a natural and comfortable position, a change to supine positioning for these intimate moments would be unlikely to be respected. Thus it appears to us that continuing the practice while ensuring non-intrusive observation of the baby during skin-to-skin contact would be the optimal approach. Indeed, other family members, if present, could be easily instructed to ensure that the infant is breathing calmly and without obstruction of the mouth and nose. If the mother is on her own, then we suggest that she not be left alone with the infant, as the period of post-labour exhaustion may well lead to a reduction in the mother's level of alertness.

Although the above are rare events, the infants who experience these frequently have extremely serious consequences, death or major disability and simple interventions to prevent such happenings are advised. After this event, our centre has developed guidelines for safe skin-to-skin at birth, which, rather than prohibiting a contact which many mothers find very satisfying after a successful labour, require a non-intrusive surveillance of the infant during this period.

Learning points

Sudden unexpected life-threatening events can occur soon after delivery of a newborn infant

- In our case, and in majority of the others, they occur during skin-to-skin contact, which appears therefore to be a risk factor

- Unobtrusive surveillance of infants during skin-to-skin contact may reduce the risks.

Competing interests None.

Patient consent Obtained.

\section{REFERENCES}

1. Hays $\mathbf{S}$, Feit $P$, Barré $P$, et al. Respiratory arrest in the delivery room while lying in the prone position on the mothers' chest in 11 full term healthy neonates. Arch Pediatr 2006;13:1067-8.

2. Espagne S, Hamon I, Thiébaugeorges 0, et al. Sudden death of neonates in the delivery room. Arch Pediatr 2004;11:436-9.

3. Gatti $\mathbf{H}$, Castel $\mathrm{C}$, Andrini P, et al. Cardiorespiratory arrest in full term newborn infants: six case reports. Arch Pediatr 2004;11:432-5.

4. Rodríguez-Alarcón J, Melchor JC, Linares A, et al. Early neonatal sudden death or near death syndrome. An epidemiological study of 29 cases. Acta Paediatr 1994;83:704-8.

5. Dageville C, Pignol J, De Smet S. Very early neonatal apparent lifethreatening events and sudden unexpected deaths: incidence and risk factors. Acta Paediatr 2008;97:866-9.

6. Branger B, Savagner C, Roze JC, et al. Eleven cases of early neonatal sudden death or near death of full term and healthy neonates in maternity wards. J Gynéco Obstat Biol Reprod (Paris) 2007:36:671-9.

7. Toker-Maimon 0, Joseph LJ, Bromiker R, et al. Neonatal cardiopulmonary arrest in the delivery room. Pediatrics 2006;118:847-8.

8. Burchfield DJ, Rawlings DJ. Sudden deaths and apparent life-threatening events in hospitalized neonates presumed to be healthy. Am J Dis Child 1991;145:1319-22. 


\section{BMJ Case Reports}

This pdf has been created automatically from the final edited text and images.

Copyright 2010 BMJ Publishing Group. All rights reserved. For permission to reuse any of this content visit http://group.bmj.com/group/rights-licensing/permissions.

BMJ Case Report Fellows may re-use this article for personal use and teaching without any further permission.

Please cite this article as follows (you will need to access the article online to obtain the date of publication).

Schrewe B, Janvier A, Barrington K. Life-threatening event during skin-to-skin contact in the delivery room. BMJ Case Reports 2010;10.1136/bcr.11.2010.3475, date of publication

Become a Fellow of BMJ Case Reports today and you can:

- Submit as many cases as you like

- Enjoy fast sympathetic peer review and rapid publication of accepted articles

Access all the published articles

- Re-use any of the published material for personal use and teaching without further permission

For information on Institutional Fellowships contact consortiasales@bmjgroup.com

Visit casereports.bmj.com for more articles like this and to become a Fellow 